\title{
Activation of ERK/MAPK in the Lateral Amygdala of the Mouse is Required for Acquisition of a Fear-Potentiated Startle response
}

\author{
Barbara Di Benedetto',2, Magdalena Kallnik', Daniela M Vogt Weisenhorn ${ }^{1,2}$, William A Falls ${ }^{3}$, \\ Wolfgang Wurst*, , 2 and Sabine M Hölter*,' \\ 'Institute of Developmental Genetics, Helmholtz Zentrum München, German Research Center for Environmental Health, Technical University \\ Munich, Germany; ${ }^{2}$ Max-Planck-Institute of Psychiatry, Molecular Neurogenetics, Munich, Germany; ${ }^{3}$ Department of Psychology, University of \\ Vermont, Burlington, VT, USA
}

\begin{abstract}
There is considerable interest in examining the genes that may contribute to anxiety. We examined the function of ERK/MAPK in the acquisition of conditioned fear, as measured by fear-potentiated startle (FPS) in mice as a model for anticipatory anxiety in humans. We characterized the following for the first time in the mouse: $(I)$ the expression of the ERK/MAPK signaling pathway components at the protein level in the lateral amygdala (LA); (2) the time course of activation of phospho-activated MAPK in the LA after fear conditioning; (3) if pharmacological inhibition of PMAPK could modulate the acquisition of FPS; (4) the cell-type specificity of PMAPK in the LA after fear conditioning. Using western blot and immunohistochemistry techniques and injecting the MEK inhibitor U0 I 26 in the LA, we showed the following: ( I ) both MEKI/MEK2 and ERKI/ERK2 were co-expressed in the LA of the adult mouse brain; (2) there is a peak of pMAPK at 60 min after fear conditioning; (3) the ERK/MAPK signaling pathway activation is essential for the acquisition of an FPS response; (4) at $60 \mathrm{~min}$, the pMAPK are exclusively neuronal and not glial. These results emphasize the importance of this signaling pathway in the acquisition of conditioned fear in the mouse. Given the widely held view that conditioned fear models the essential aspects of anxiety disorders, the results confirm the ERK/MAPK signaling pathway as a molecular target for the treatment of anxiety disorders in the clinic. Neuropsychopharmacology (2009) 34, 356-366; doi: I0.1038/npp.2008.57; published online 23 April 2008
\end{abstract}

Keywords: anxiety; amygdala; ERK/MAPK; fear-potentiated startle; mouse

\section{INTRODUCTION}

Anxiety disorders are serious medical illnesses, which affect up to $10 \%$ of the adult population, with a high financial burden on the world's health systems (Kaufman and Charney, 2000). Consequently, a great deal of effort has been made to understand their neurobiological basis. In the laboratory, Pavlovian fear conditioning is often used to model the essential attributes of anxiety. In the conditioned fear procedure, a neutral stimulus such as a tone is paired with an aversive stimulus, such as a footshock. Thus, the tone acquires the ability to elicit a variety of behaviors indicative of fear and anxiety. Using these procedures, the amygdala has been identified as an essential structure in the neural circuit for conditioned fear and some molecular

*Correspondence: Dr SM Hölter, Institute of Developmental Genetics, Helmholtz Zentrum München-German Research Center for Environmental Health, Ingolstaedter Landstrasse I, Neuherberg/Munich, Bayern 85764, Germany, Tel: +4989 3187 3674, Fax: + 4989 3187 3099, E-mail: hoelter@helmholtz-muenchen.de or Dr W Wurst, Tel: + 49893187 4l10, Fax: + 49893187 3099, E-mail: wurst@helmholtz-muenchen.de

Received 14 October 2007; revised 30 January 2008; accepted 6 March 2008 events in this region which contribute to conditioned fear (Bauer et al, 2002; Paul et al, 2007; Rattiner et al, 2004; Schafe et al, 2000).

Among the signaling pathways studied for their role in fear conditioning, the MAPK pathway is one of the most analyzed for its role in the lateral amygdala (LA) of the rat (Schafe et al, 2000). The model proposed shows that the MEK1/2 $\rightarrow$ ERK1/2 cascade is activated downstream of $N$ methyl-D-aspartate (NMDA) receptors and voltage-gated calcium channels in the LA in response to sensory stimuli as tone and footshock, when these are paired during Pavlovian fear conditioning (for a review, see Blair et al, 2001; Schafe et al, 2001).

With the advent of transgenic technologies, mouse models have become the chosen method in investigating the role of genes in complex behaviors. Although conditioned fear is strongly conserved across species, its molecular control may differ even in highly related species as the rat and the mouse. Indeed, we recently showed that the expression pattern of components of the MAPK pathway in adult rat and mouse brains can differ at the mRNA level (for a comparison, see Thomas and Hunt, 1993 and Di Benedetto et al, 2007). Therefore, despite the well-described role of MAPKs in fear conditioning in rats, given their 
differential expression patterns in rat and mouse, the goal of this study was to investigate the role of MAPKs in fear conditioning in mice.

A subgoal of the study was to propose a differential role of neuronal MAPK from glial MAPK, as recently some studies started proposing an active participation of glia cells in regulating stimulus-dependent synaptic activity (Nishiyama et al, 2002; Todd et al, 2006). It was shown that astrocytes can release glutamate in response to intracellular increases in $\mathrm{Ca}^{2+}$ concentrations, thus regulating the activity of neighboring neurons (Parpura and Haydon, 2000). As $\mathrm{Ca}^{2+}$ in neurons modulates the activation of intracellular signaling pathways such as MAPK, MAPKs could also be activated in glia cells due to $\mathrm{Ca}^{2+}$ increases during fear learning.

Fear-potentiated startle has proven to be a useful method for examining conditioned fear to study anxiety disorders (for a review, see Cryan and Holmes, 2005). In fact, FPS shows the following: (1) face validity, as the responses observed in the animal models reproduce the symptoms of anxiety disorders (Grillon et al, 1991, 1994); (2) construct validity in rodents as model for humans, as the neural circuits underlying the startle responses have been well characterized in rodents and showed strong similarities with humans (Davis, 1992; Heldt et al, 2000; LaBar et al, 1998; Phelps et al, 2001); (3) predictive validity, as clinically effective anxiolytic drugs reduced the FPS in rodents (Bitsios et al, 1999; Risbrough et al, 2003), but see (Baas et $a l, 2002)$. In the FPS procedure, conditioned fear is operationally defined as elevated startle amplitude in the presence versus the absence of a stimulus that was previously paired with shock.

The Falls laboratory has initially characterized FPS in mice, comparing the efficiency in acquisition of fear potentiation in different inbred mouse strains (Falls, 2002; Falls et al, 1997). They also showed that it is amygdala dependent (Heldt et al, 2000) and that it can be used to characterize the involvement of specific molecules in the acquisition of fear learning (Falls et al, 2000).

To further characterize the molecular mechanisms involved in conditioned fear in adult mice, this study aimed at investigating the following: (1) the expression pattern of MEK1/MEK2 and ERK1/ERK2 proteins in the LA; (2) the time course of activation of ERK/MAPK in the LA after fear conditioning; (3) if pharmacological inhibition of the ERK/ MAPK signaling pathway in the LA impairs acquisition of FPS; (4) the cell-type specificity of activated ERK/MAPK in LA after fear conditioning.

\section{MATERIALS AND METHODS}

\section{Animals}

Seven-week-old C57BL/6J male mice (Charles River, Sulzfeld, Germany) were delivered and were group housed in individually ventilated cages (IVC); after acclimating, they were individually housed and maintained on a $12 \mathrm{~h}$ light/ dark cycle with food and water available ad libitum until the day of the experiment. Experiments on animals were carried out in accordance to the European Communities Council Directive of 24 November 1986 (86/609/EEC).

\section{Fear-Conditioning Apparatus and Behavioral Procedure}

Fear-potentiated startle was assessed using a commercially available startle apparatus and software from Med Associates Inc. (Burlington, VT, Startle Stimulus Package PHM-255A, ANL-925C Amplifier). Training and testing were conducted in transparent plastic cylinders $(4.3 \mathrm{~cm}$ in diameter, $12.5 \mathrm{~cm}$ in length), fixed on a plastic platform, with cradle-shaped grids mounted on their floors to deliver footshocks (controlled by Stand Alone Shockers, ENV-414s-SR). Highfrequency speakers were mounted behind each cylinder to produce the acoustic stimuli. Cylinder movements were measured by a stabilimeter and amplified and digitized in arbitrary units using the 'Advanced Startle' software.

Experiments were performed between 10.00 and 18.00 on 9-week-old mice. The FPS procedure consisted of preconditioning test, conditioning and post-conditioning test, with a $24 \mathrm{~h}$ delay between conditioning and post-conditioning test. The pre-conditioning test is necessary to establish a baseline level of startle response to the tone before conditioning. Startle stimuli were bursts of 95, 100 and $105 \mathrm{~dB}$ intensities, $20 \mathrm{~ms}$ duration. The pre- and postconditioning tests started with $5 \mathrm{~min}$ acclimation followed by nine startle stimulus alone trials (each intensity presented three times randomly) that were excluded from statistical analysis. After these nine leaders, six trial types were presented three times each randomly, with $60 \mathrm{~s}$ inter trial intervals (ITI): three cue trials, in which the cue (CS, $12 \mathrm{kHz}$ tone, $60 \mathrm{~dB}, 30 \mathrm{~s}$ ) immediately preceded each startle stimulus intensity ('CS + STL'), and three startle stimulus alone ('STL alone') trials at each intensity. Startle amplitude was defined as the maximal peak-to-peak voltage deflection occurring within $100 \mathrm{~ms}$ after the onset of the startle stimulus. Mean startle amplitudes were calculated over each startle stimulus intensity for cue and STL trials. Percent FPS was defined as increase in percent response to CS from preto post-conditioning tests and was computed according to the formula: $\left\{((C S+S T L)-S T L\right.$ alone $) / S T L$ alone ${ }^{\star} 100$. The protocol for fear conditioning started with $5 \mathrm{~min}$ acclimation followed by 10 trials of $30 \mathrm{~s}$ tone coterminating with a $0.5 \mathrm{~s}, 0.5 \mathrm{~mA}$ footshock (ITI between 60 and $180 \mathrm{~s}$ ). This protocol was chosen as it gave the highest and reproducible fear response on C57BL/6J mice in our housing conditions (IVC) (Supplementary Figure S1).

\section{Western Blotting}

Ten-week-old mice $(n=3)$ were euthanized with $\mathrm{CO}_{2}$ and brains removed. Amygdalae were dissected on ice from 400$\mu \mathrm{m}$-thick vibratome sections under a binocular microscope. Care was taken to only dissect the LA nucleus. However, given its small size, there is some likelihood that portions of adjacent areas were included. Samples were homogenized in ice-cold RIPA buffer, concentrations were determined with BSA standards and Laemmli buffer was added to them; $15 \mu \mathrm{g}$ of total proteins/sample were denatured, electrophorased on a 10\% SDS-PAGE gel and blotted on PVDF membrane (Pall, Pensacola, FL). Membrane was blocked in $5 \%$ skim milk in TBS-T, $24 \mathrm{~h}$ at $4^{\circ} \mathrm{C}$ and incubated with rabbit anti-MEK1 (1:1000, Santa Cruz Biotechnology, Santa Cruz, CA) or mouse anti-MEK2 $(1: 2500$, BD Transduction Laboratories, Franklin Lakes, NJ) or rabbit anti-ERK1/2 
( $1: 1000$, Cell Signaling Technology, Beverly, MA), $1 \mathrm{~h}$ at room temperature (RT). Blots were washed in TBS-T and incubated with HRP-goat anti-rabbit or HRP-goat antimouse (respectively $1: 5000$ and $1: 1000$, Jackson ImmunoResearch, Cambridgeshire, UK), $1 \mathrm{~h}$ at RT. After washing, they were visualized with ECL (Amersham Biosciences, Arlington Heights, IL) and films were scanned and processed with Adobe Photoshop.

\section{Behavioral Procedure and Tissue Preparation for Immunohistochemistry}

To examine the time course of MAPK activation, 9-week-old mice were trained, euthanized 5, 15, 30,60 or 180 min after training and perfused with ice-cold $4 \%$ paraformaldehyde in PBS for 7 min. Box control ('Box ctrl') mice were handled and exposed to the conditioning box for an equivalent amount of time $(23 \mathrm{~min})$, but were not exposed to tones or shocks. Mice for the control experiment were exposed to only the tone, only the footshock or to explicitly unpaired tone and shock presentations, euthanized $60 \mathrm{~min}$ later and processed as described above. Brains were removed, postfixed $24 \mathrm{~h}$ at $4{ }^{\circ} \mathrm{C}$ and cryoprotected in $25 \%$ sucrose in PBS $24 \mathrm{~h}$ at $4{ }^{\circ} \mathrm{C}$. Cryosections $(30 \mu \mathrm{m})$ were cut and kept in $30 \%$ ethylene glycol $/ 30 \%$ glycerol in $\mathrm{PBS}$ at $-20^{\circ} \mathrm{C}$ until processed.

\section{Immunohistochemistry and Immunofluorescent- Immunohistochemistry}

For detection of phosphorylated proteins, $0.1 \mathrm{mM} \mathrm{NaF}$ was included in all buffers and solutions. For immunohistochemistry (IHC), sections were processed as described (Valjent et al, 2004). For immunofluorescent-immunohistochemistry (IF-IHC): sections were pretreated as for IHC, but PBS was used instead of TBS as buffering agent and, at the end, sections were incubated with rabbit anti-phosphoERK1/2, together with either mouse anti-NeuN $(1: 200$, Chemicon, Temecula, CA) or mouse anti-S100 $\beta(1: 1000$, Sigma, St Louis, MO) in 10\% Normal Goat Serum $/ 0.5 \%$ Triton X-100 in PBS, $24 \mathrm{~h}$ at $4^{\circ} \mathrm{C}$. On the second day, sections were washed and incubated $24 \mathrm{~h}$ at $4^{\circ} \mathrm{C}$ with the secondary fluorophore-conjugated antibodies (FITC-antirabbit, Dianova, Hamburg, Germany, and TRITC-antimouse IgG1, Southern Biotech, Birmingham, AL). On the third day, sections were washed and mounted onto poly-Llysine-coated slides for confocal analysis.

\section{Microscopy Data Analysis}

For the quantification of phospho-MAPK labeled cells, three to six brains were examined for each control group and each time point and data analyzed with a one-way ANOVA followed by Fisher post hoc test. In each brain, nine sections between -1.22 and $-2.30 \mathrm{~mm}$ posterior to bregma were selected for scoring. At these levels, the nuclei of the LA are clearly identifiable. Cells were counted only when the nuclei were clearly labeled and actual counts were obtained with a $40 \times$ oil-immersion objective. To estimate the total number of labeled cells, we used the Optical Fractionator and analyzed data with the StereoInvestigator Software (MicroBrightField, Colchester, VT). For the characterization of the cell-type specificity, brains were examined using confocal microscopy (Olympus, Hamburg, Germany). Sections through amygdalae were analyzed running from anterior to posterior levels, on both left and right sides, in four brains for each antibody's combination.

\section{Drugs}

The MEK inhibitor U0126 (Promega, Madison, WI) was dissolved in DMSO to a final stock concentration of $4 \mathrm{mg} / \mathrm{ml}$. For behavioral studies, the drug was diluted in aCSF $(5 \mathrm{mM}$ D-glucose, $1 \mathrm{mM} \mathrm{CaCl}, 125 \mathrm{mM} \mathrm{NaCl}, 1 \mathrm{mM} \mathrm{MgCl} 2,27 \mathrm{mM}$ $\mathrm{NaHCO}_{3}, 0.5 \mathrm{mM} \mathrm{KCl}, 0.5 \mathrm{mM} \mathrm{Na} 2 \mathrm{SO} 4,0.5 \mathrm{mM} \mathrm{NaH} \mathrm{H}_{2} \mathrm{PO}$, $1.2 \mathrm{mM} \mathrm{Na} \mathrm{NPO}_{2} \mathrm{HP}$ ). U0126 is a specific inhibitor of MEK proteins and shows no effect on other kinases, such as PKA, calcium-calmodulin kinase II or PKC (Roberson et al, 1999).

\section{Behavioral Procedure and Drug Infusion}

Eight-week-old mice were implanted bilaterally with guiding cannulae (PlasticOne, Roanoke, VA) aimed at the LA. Coordinates (from The Mouse Brain Atlas; Paxinos and Franklin, 2001) were as follows: $-1.7 \mathrm{~mm}$ anteroposterior, $\pm 3.4 \mathrm{~mm}$ mediolateral, and $-3.4 \mathrm{~mm}$ dorsoventral. Guiding cannulae were glued to the skull and plugged with dummy cannulae (PlasticOne) to prevent clogging. After one week of recovery, mice were tested for their baseline preconditioning startle responses to the tone, and immediately afterward, habituated to dummy cannulae removal for at least $10 \mathrm{~min}$ for each mouse. On the day of conditioning, mice were infused bilaterally with either $0.3 \mu \mathrm{l} /$ side of $50 \%$ DMSO/aCSF (vehicle) or $1.0 \mu \mathrm{g}$ U0126/0.3 $\mu \mathrm{l} /$ side in $50 \%$ $\mathrm{DMSO} / \mathrm{aCSF}$. Injections were performed at the rate of $0.1 \mu \mathrm{l} / \mathrm{min}$ in freely moving mice and injectors (PlasticOne) remained in the cannulae for $1 \mathrm{~min}$ more, to allow diffusion of the drug from the tip. Thirty minutes after infusions, mice were trained and tested $24 \mathrm{~h}$ later, as described. Data were analyzed with a two-way ANOVA followed by Bonferroni post hoc correction. Increases in the percent of response to CS were considered significant if $p \leqslant 0.05$. One week after the pharmacological manipulations, the same animals were retrained and retested (reconditioning), $24 \mathrm{~h}$ later, to check the specificity of pharmacological inhibition. The absence of fear potentiation after reconditioning was used to exclude animals from data analysis, as this could be due to amygdala damage following injections. At the end of each experiment, mice were euthanized and brains prepared as described above. Sections were cut through the area of the amygdala and histological examination was used to verify the location of injection sites. Incorrect positioning of injector tips was used as a second criterion to exclude animals from data analysis. With these criteria, 24 animals were excluded from data analysis and were separately analyzed (Figure $4 \mathrm{c}$ ).

\section{RESULTS}

\section{Protein Expression of ERK/MAPK Signaling Pathway Components in the LA of the Adult Mouse}

To examine the expression of MEK1, MEK2, ERK1, and ERK2 in the LA of the mouse at the protein level, we 
performed a western blot analysis. Total proteins were extracted from tissue of the LA nucleus after dissection of amygdalae from adult mouse brains. As shown in Figure 1, all four proteins were present in the LA (columns A, B, and $\mathrm{C}$ represent three different mouse brains). To our knowledge, it was never shown that these four MAPK signaling pathway components are coexpressed in the LA nucleus of the adult mouse brain. Interestingly, even though the mRNA for Mek2 was absent from most of the regions of the adult mouse brain, including the LA (Di Benedetto et al, 2007), at the protein level, it was present.

\section{Time Course of Activation of ERK/MAPK Signaling Pathway in the Amygdala of the Mouse After Fear Conditioning}

After the establishment of a reliable protocol to induce the acquisition of a FPS response in C57BL/6J mice (Supplementary Figure S1), we used it to study the time course of pMAPK after fear conditioning. We used immunohistochemistry (IHC) to anatomically localize expression of pMAPK to particular amygdala nuclei. Using an antibody that selectively recognizes activated phosphorylated ERK/ MAPK, we found labeled cells scattered throughout the LA. Some cells could also be seen in adjacent regions around the LA, as shown in Figure $2 \mathrm{c}-\mathrm{h}$, but they were not included in the statistical analysis. To date, there are no published reports using a stereological method to count the total numbers of phospho-activated MAPK labeled cells in the LA of rodents. This method allows an unbiased estimate of the total number of the cells of interest within a selected tissue, involving a systematic, uniformly random sampling of that tissue (Gundersen et al, 1988). A one-way ANOVA showed an overall significant difference in the number of cells

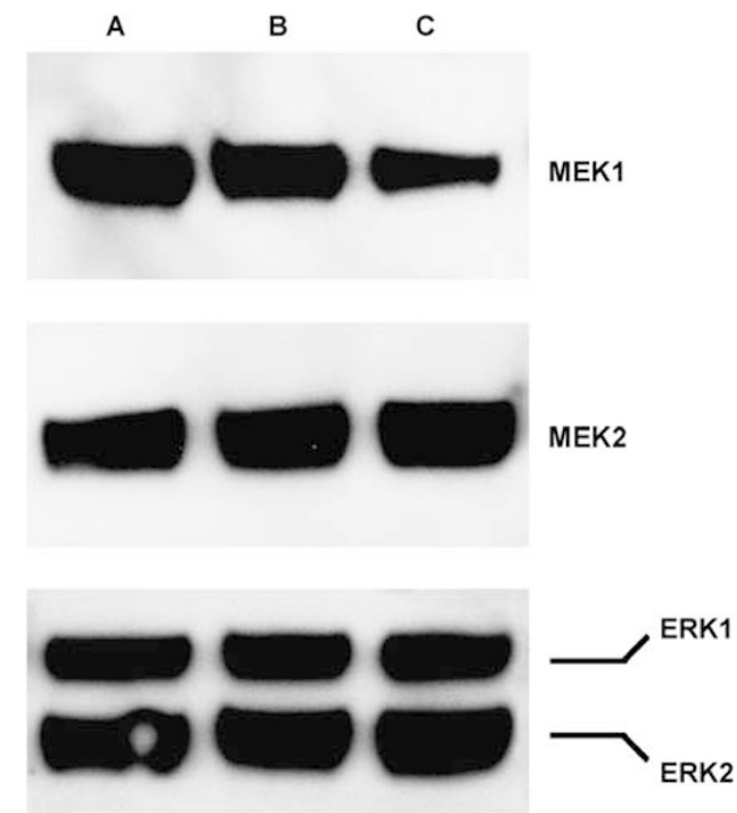

Figure I Western blot of $L A$ samples to characterize the expression of $\mathrm{MEKI} / 2$ and ERKI/2 proteins. Lanes $\mathrm{A}-\mathrm{C}$ show the results of the immunoblotting analysis from three independent dissection experiments. Total protein extracts were taken from LA nucleus tissue, dissected from vibratome $400-\mu$ m-thick sections of adult mouse brains. among the groups dependent on time $\left(\mathrm{F}_{(5)}=2,80\right.$, $\left.{ }^{\star} p \leqslant 0.05\right)$. A Fisher post hoc test revealed that that only the number of pMAPK at 60 min after fear conditioning was significantly higher than that in the Box ctrl group (Figure 2b). To evaluate whether the observed activation of PMAPK after fear conditioning was due to the associative specificity of tone/shock pairings or to nonassociative memory components as auditory stimulation or footshock sensitization, we performed an additional control experiment where mice were given four different types of stimulation, followed $60 \mathrm{~min}$ later by perfusion: ten tones without shocks ('tone'), ten shocks without tones ('shock'), ten explicitly unpaired presentations of tone and shock ('unpaired'), and ten tone-shock pairings ('paired'). As we could not know whether the labeling in these groups reflected basal levels of pMAPK, we included again a (fifth) Box ctrl group, as done for the previous experiment. For the 'unpaired' group, the unconditioned stimulus (shock) preceded the conditioned stimulus (tone) by 30-90 s, and 30-90 s was the ITI between a CS and the next trial. The ANOVA showed an overall significant effect for group $\left(\mathrm{F}_{(4)}=5,08 ;{ }^{*} p \leqslant 0.01\right)$, with the Fisher post hoc test revealing that only the number of pMAPK labeled cells in the 'paired' group was significantly higher than that in the Box ctrl group (Figure 3a). Notably, no differences occurred in the two experiments between either the Box ctrl groups (n.s. $p=0.089$ ), or the 'paired' groups at $60 \mathrm{~min}$ after conditioning (n.s. $p=0.445$ ).

Effect of the Pharmacological Inhibition of ERK/MAPK in the Amygdala on Acquisition of FPS in the Mouse

Analysis of acquisition of cue-potentiated startle. Previous experiments showed that in rats the ERK/MAPKs are transiently activated in the LA during associative tone and shock pairing (Schafe et al, 1999, 2000). Moreover, recent studies using targeted pharmacological manipulations in the amygdala implicated the ERK/MAPK signaling pathway in acquisition/consolidation of fear conditioning. Specifically, it was shown that, in the rat, blockade of this signaling pathway can impair the freezing response $24 \mathrm{~h}$ after conditioning (Schafe et al, 2000). It is not known whether the same applies to fear conditioning in mice. Therefore, we asked whether activation of ERK/MAPK in this region was required for acquisition of a fear-potentiated startle response in the mouse. We pharmacologically inhibited the MEK1/2 proteins through local injection of U0126, a specific inhibitor of these molecules that are direct upstream activators of ERK/MAPKs. Because of our previous results showing a peak of PMAPK at 60 min after conditioning, we injected the pharmacological inhibitor $30 \mathrm{~min}$ before conditioning to ensure coverage of this time window. As shown in Figure 4b, bilateral injection of U0126 before conditioning impaired the acquisition of a conditioned fear response. A two-way ANOVA for repeated measures showed that responses to CS were dependent on treatment (conditioning $\times$ treatment interaction: $\mathrm{F}_{(1,10)}=19.43$, ${ }^{* *} p \leqslant 0.01$; conditioning: $\left.\mathrm{F}_{(1,10)}=25.59, \quad{ }^{* * *} p \leqslant 0.001\right)$. The tone/footshock pairing increased the response to CS in vehicle-treated animals $\left({ }^{*} p \leqslant 0.05\right)$, but not in U0126-treated animals (n.s. $p=0.396$ ) (Figure $4 b$ ). No significant difference was found between the two groups 
a

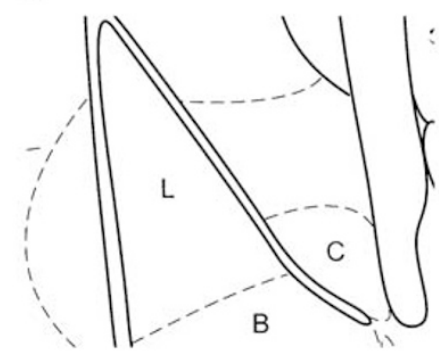

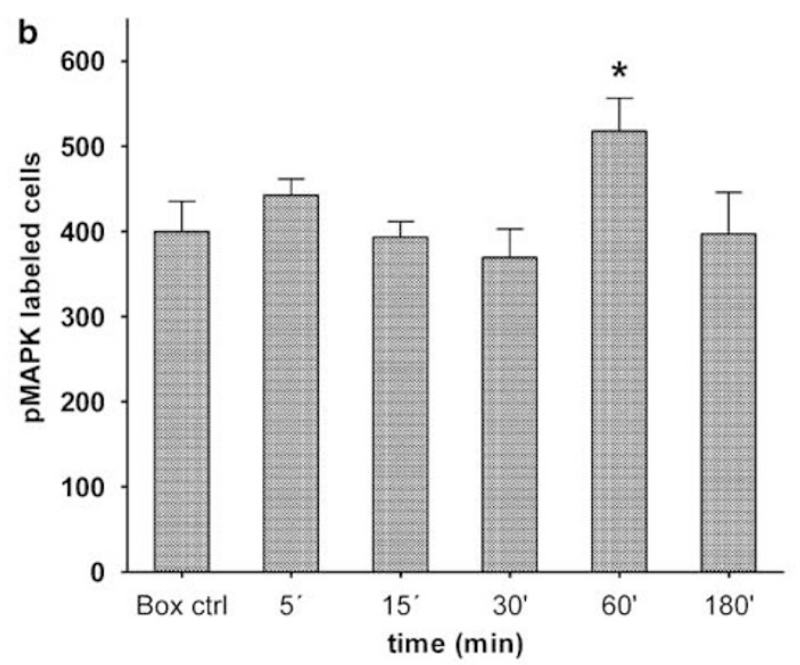
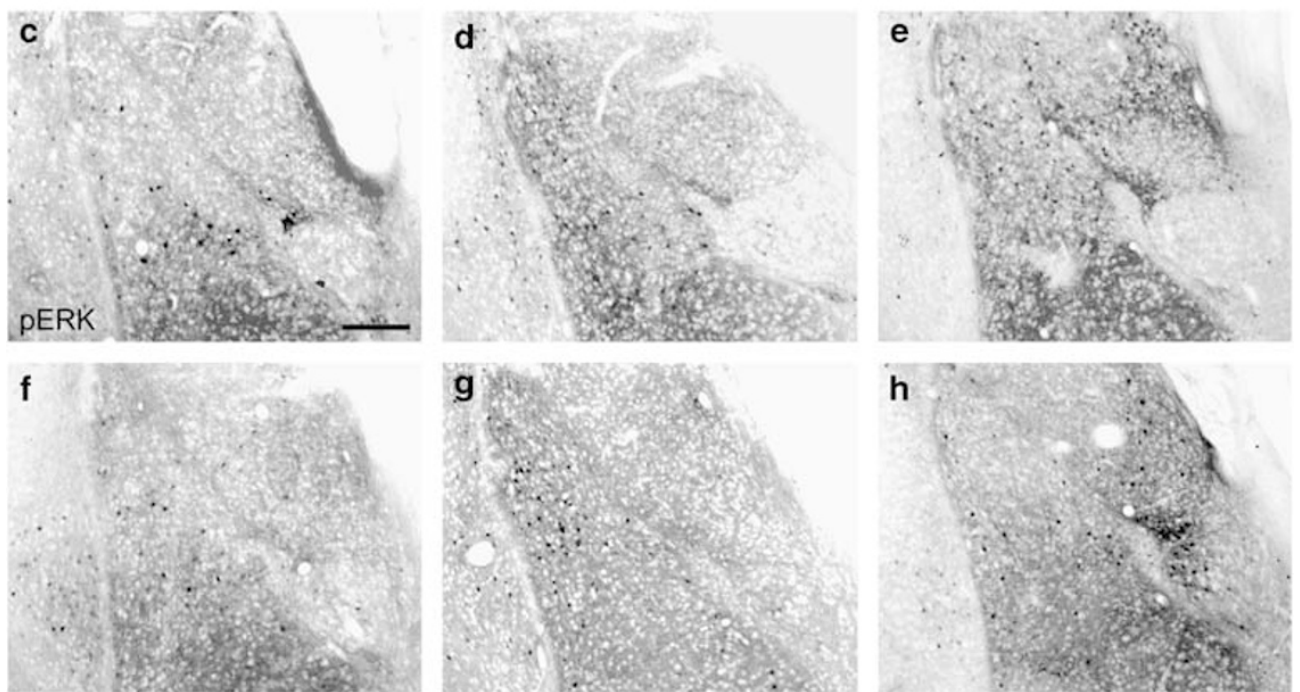

Figure 2 Time course of activation of PMAPK in LA after fear conditioning. (a) Schematic representation of the amygdala at approximately - I.82 from bregma (according to Paxinos and Franklin, 200I); (b) Mean \pm SEM of pMAPK immunoreactive cells in sham-trained controls (Box control, ctrl) ( $n=3$ ) and $5 \mathrm{~min}(n=3), 15 \mathrm{~min}(n=5), 30 \mathrm{~min}(n=7), 60 \mathrm{~min}(n=7), 180 \mathrm{~min}(n=4)$ after conditioning (ANOVA; * $p \leqslant 0.05)$; (c) Representative photomicrographs of pMAPK labeling in the LA in sham-trained controls (Box ctrl); (d-h) Representative photomicrographs of pMAPK labeling in the LA at 5 min (d), I5 min (e), $30 \mathrm{~min}(\mathrm{f}), 60 \mathrm{~min}(\mathrm{~g}), 180 \mathrm{~min}(\mathrm{~h})$ after fear conditioning. Scale bar $=200 \mu \mathrm{m}$.

in pre-conditioning responses (n.s. $p=0.079$ ). These differences in acquisition of fear-potentiated startle produced by preconditioning infusions of U0126 were not attributed to permanent damage of the amygdala or to a modification in perception of the US due to the pharmacological manipulation. Following drug-free reconditioning, both groups of mice showed robust FPS. A two-way ANOVA showed a significant effect of reconditioning in both vehicle- and U0126-treated animals (conditioning: $\mathrm{F}_{(1,10)}=27.11,{ }^{* *} p \leqslant 0.001$; conditioning $\times$ treatment interaction: $\mathrm{F}_{(1,10)}=0.49$, n.s. $p=0.501$ ) (Figure $4 \mathrm{~b}$ ). This confirmed that the blockade of conditioned fear by U0126 was due to the specific, transient effect of the pharmacological compound and not to a permanent damage of the amygdalae consequent to injections or to an unspecific effect of the compound on perception of the US. To address the specificity of injection in the amygdala, we analyzed the behavioral results from animals in which injection was considered outside of the amygdala by histological analysis (Figure 4c). Here, the ANOVA showed that both groups learned the task after conditioning (conditioning: $\mathrm{F}_{(1,22)}=16,57,{ }^{* *} p \leqslant 0.01$; conditioning $\times$ treatment interac-

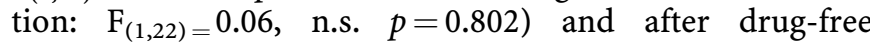
reconditioning (conditioning: $\mathrm{F}_{(1,22)}=40,25$, ${ }^{* * *} p \leqslant 0.001$;

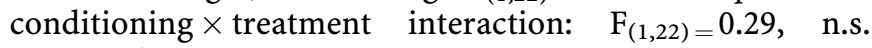
$p=0.597)$.

Analysis of acquisition of context-potentiated startle. After tone/footshock pairings, it was also expected to get an increase in post-conditioning baseline startle responding due to conditioned fear elicited by contextual cues. Indeed, as showed in Figure $4 \mathrm{~d}$, a tendential enhancement of the startle amplitude was evident in both groups, when preto post-conditioning responses were compared (conditioning: $\mathrm{F}_{(1,10)}=4.36, p=0.063$; conditioning $\times$ treatment interaction: $\mathrm{F}_{(1,10)}=0,77$, n.s. $\left.p=0.4\right)$, indicating that indeed context learning occurred. When considering the reconditioning, the already observed enhancement of the startle amplitude was even intensified, as here the startle amplitude enhancement reached significant levels in both 

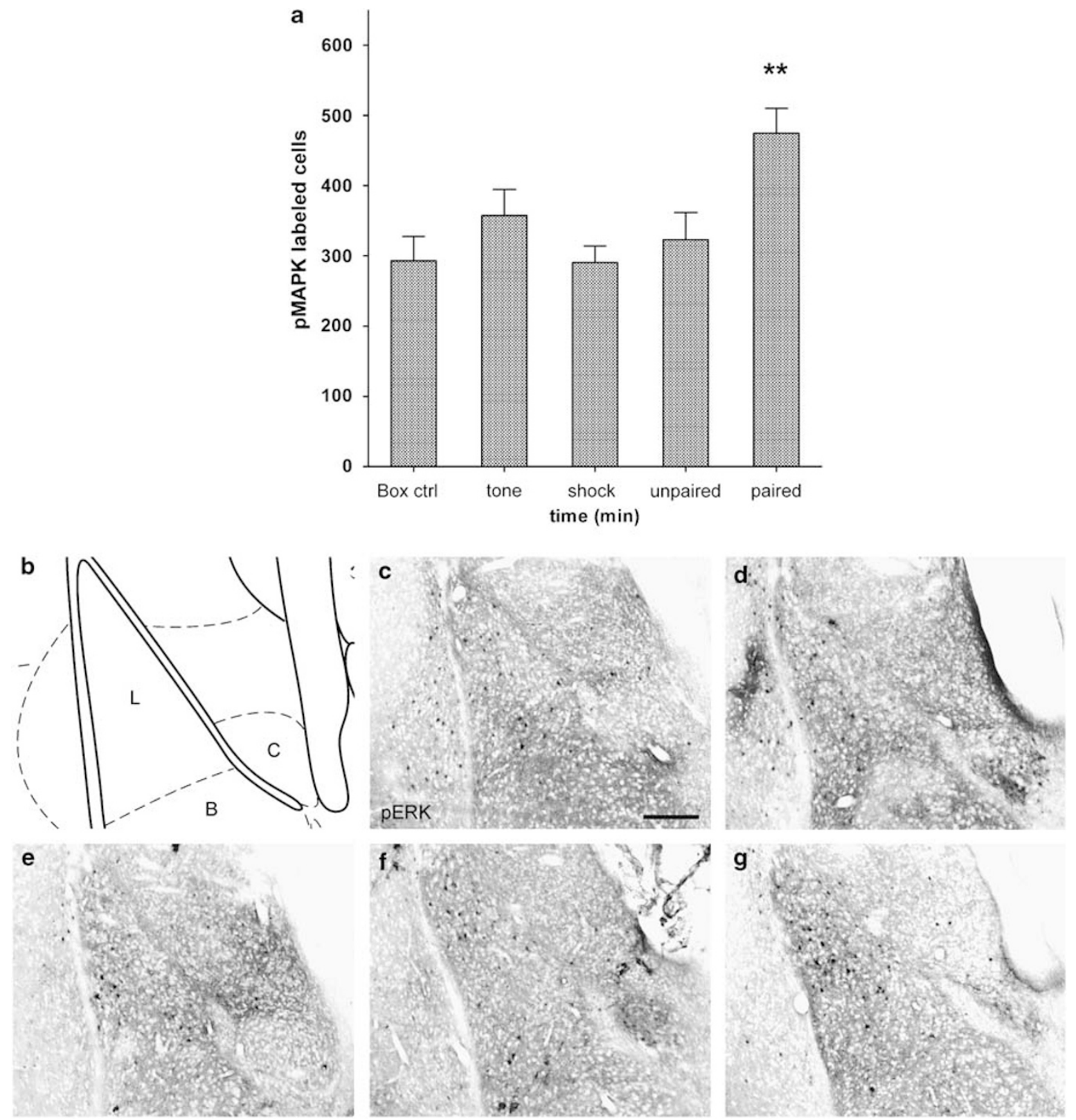

Figure 3 Specificity of associative tone-shock pairing for activated PMAPK in LA after fear conditioning. (a) Mean \pm SEM of pMAPK immunoreactive cells in: sham-trained controls (Box ctrl) $(n=5)$ and tone-alone $(n=3)$, shock-alone $(n=4)$, unpaired $(n=5)$, and paired $(n=5)$ groups after conditioning (ANOVA; ** $\leqslant 0.0 \mathrm{I}$ ); (b) schematic representation of the amygdala at approximately - I.82 from bregma (according to Paxinos and Franklin, $200 \mathrm{I}$ ); (c-g) representative photomicrographs of PMAPK labeling in the LA in sham-trained controls (c) and animals that received tone-alone (d), shockalone (e), unpaired $(\mathrm{f})$, and paired $(\mathrm{g})$ stimuli presentations. Scale bar $=200 \mu \mathrm{m}$.

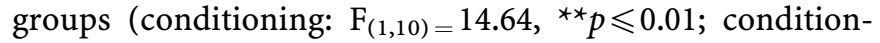
ing $\times$ treatment interaction: $\mathrm{F}_{(1,10)}=0.09$, n.s. $\left.p=0.773\right)$. Therefore, in contrast with the cue-conditioning results, context-dependent learning took place in both groups postconditioning and post-reconditioning, independent of the treatment.

\section{Analysis of Activated ERK/MAPK in the LA in Neurons or Glial Cells After Fear Conditioning}

We used fluorescent IHC to investigate the colocalization of pMAPK with a specific neuronal or glial marker. To label neurons, we chose the antibody NeuN, which recognizes a nuclear protein (Baekelandt et al, 2000); and for glia cells, we used an antibody against the calcium-binding protein S100 $\beta$ (Nishiyama et al, 2002). Staining was performed on sections derived from mice euthanized at $60 \mathrm{~min}$ after conditioning, when the increase in PMAPK in LA was most prominent. The IF-IHC was performed on parallel sections, each of which was labeled with one of the two antibody combinations, namely pMAPK/NeuN or pMAPK/S100 $\beta$. Despite the suggestion that glia cells may actively participate in the regulation of stimulus-dependent synaptic activity (Nishiyama et al, 2002; Todd et al, 2006), the analysis showed that all the pMAPK-positive cells were co-labeled with NeuN (Figure 5b and c); however, none was 
a

Bregma
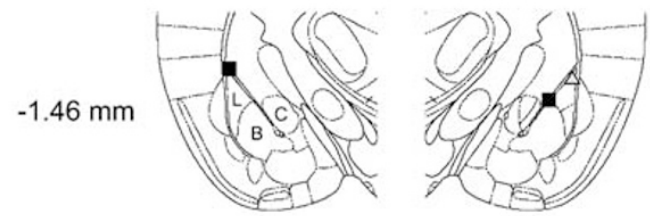

$-1.70 \mathrm{~mm}$
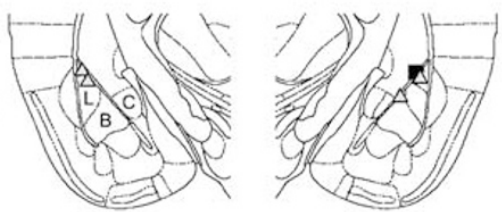

$-1.94 \mathrm{~mm}$
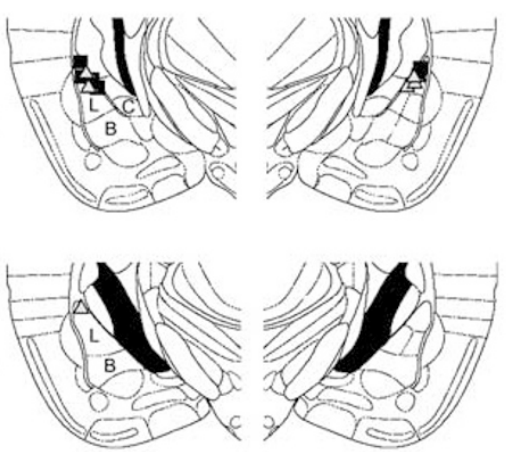

= vehicle

$\Delta=\mathrm{U} 0126$
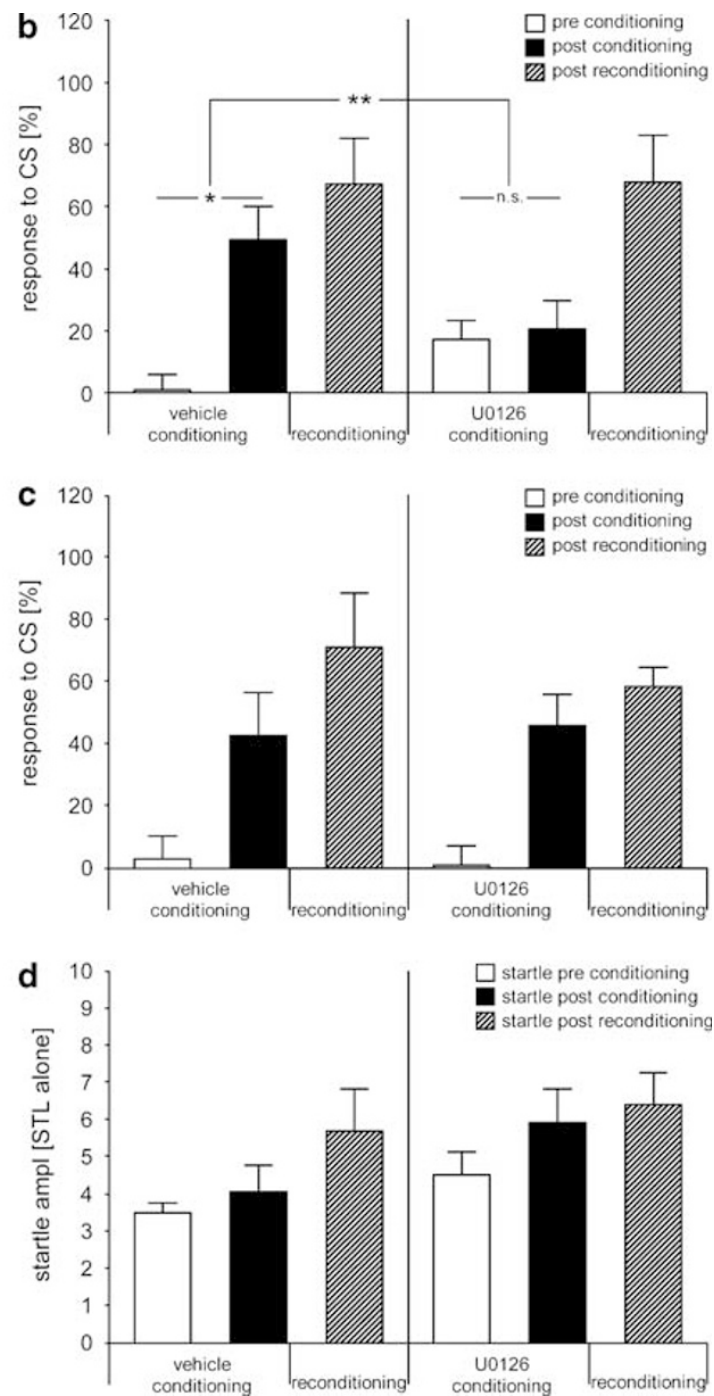

Figure 4 Impairment in acquisition of the FPS after intra-LA infusions of the MEK inhibitor U0I26. (a) Schematic drawing (redrawn from Paxinos and Franklin, 200 I) representing the sites of injections of the vehicle (black filled square) or the pharmacological inhibitor U0 I 26 (grey-filled triangle). L, lateral amygdala; B, basal amygdala; C, central amygdala. (b) Mice received bilateral intra-LA injections of either 50\% DMSO in aCSF (vehicle) or U0I26 in 50\% DMSO in aCSF 30 min before conditioning and were tested $24 \mathrm{~h}$ later. Vehicle-injected mice $(n=5)$ showed acquisition of fear potentiation (as increase in the percent of response to CS) that was not seen in U0I26-injected mice $(n=7)$ (ANOVA; n.s., not significant; * $p \leqslant 0.05 ; * * * 0.0$ I). As described in the text, these differences in acquisition of fear-potentiated startle were not attributed to permanent damage of the amygdala, but to a specific effect of the pharmacological inhibition, as verified by the reconditioning experiment. (c) The specificity of amygdalar pharmacological inhibition was showed by the analysis of mice that received infusions of the vehicle $(n=||)$ or the $\operatorname{Ul} 26(n=\mid 3)$ outside the amygdala (ANOVA; $p \leqslant 0.0 I)$, but not a conditioning $\times$ treatment interaction; the same was reconfirmed after reconditioning (ANOVA; $p \leqslant 0.00 \mathrm{I}$ ). (d) Changes in startle baseline responses were analyzed to evaluate the acquisition of context-potentiated startle. As expected, we could observe a trend to increases in startle responses in both vehicleand $\cup 0 \mathrm{I} 26$-injected mice (ANOVA; $p=0.063$ ), which reached significance after reconditioning (ANOVA; $p \leqslant 0.0 \mathrm{I}$ ), as they were trained and tested in the same chambers. But we could not find any interactions between conditioning and treatment (ANOVA; $p=0.4$ ).

colocalized with the $\mathrm{S} 100 \beta$ antibody (Figure $5 \mathrm{~d}$ and e). Thus, this strongly suggested that the peak of activation of pMAPK at 60 min after fear conditioning was exclusively neuronal, without involvement of glia cells.

\section{DISCUSSION}

The primary goal of this study was the molecular and pharmacological validation of the mouse to perform further studies aimed at understanding the role of specific genes in psychiatric diseases. We could demonstrate the following: (1) both MEK1/MEK2 and ERK1/ERK2 are coexpressed in the LA of the adult mouse brain at the protein level; (2) there is a peak of activated pMAPK in the LA at 60 min after fear conditioning; (3) the ERK/MAPK signaling pathway activation is essential for the acquisition of a FPS response in the mouse; and (4) the peak of pMAPK at $60 \mathrm{~min}$ is exclusively neuronal and not glial.

\section{MEK1/2 and ERK1/2 Proteins are All Expressed in the LA of the Mouse}

The actual model for fear learning proposed with studies done in rats (for a review, see Blair et al, 2001; Schafe et al, 2001) sees the activation of the ERK/MAPK signaling pathway downstream of NMDA receptors coincident with 
a

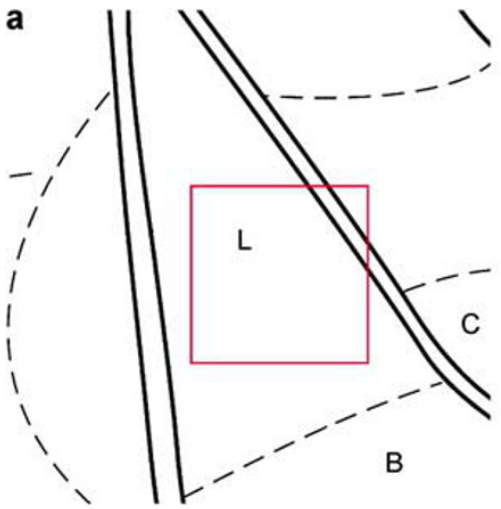

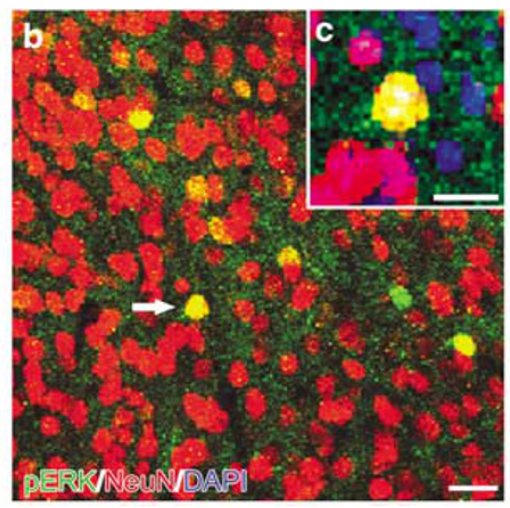

Figure 5 Cell-type specificity of phospho-activated MAPK after fear conditioning. (a) Schematic drawing of lateral (L), basal (B), and central (C) amygdala (redrawn from Paxinos and Franklin, 200 I); (b) Representative photomicrograph ( $\times 20$ ) of a portion of the LA (red square in (a)) immunostained with PMAPK (green) and NeuN (red) at 60 min after fear conditioning; the yellow color of the 'merge' between the green pMAPK and the red NeuN immunostainings shows the colocalization of the two signals; (c) Higher magnification of labeled cells (white arrow in b), in which the counterstaining with DAPI (blue) shows the single-cell nuclei; (d) Representative photomicrograph $(\times 20)$ of a portion of the LA (red square in (a)) immunostained with pMAPK (green) and $\mathrm{SIOO} \beta$ (red) at 60 min after fear conditioning; in contrast with (b), the 'merge' between the green pMAPK immunostaining with the red SIOO $\beta$ shows no colocalization of the two signals; (e) Higher magnification of labeled cells (white arrow in c), in which the counterstaining with DAPI (blue) shows the single-cell nuclei. Scale bar $=20 \mu \mathrm{m}$ in b, d; $10 \mu \mathrm{m}$ in $\mathrm{c}$, e.

Pavlovian fear conditioning. Usually, it is postulated that the ERK/MAPK (ERK1/2) are phosphorylated by their upstream activator proteins MEK1 and MEK2 and translocated into the nucleus to exert their function. But so far there was no formal proof that MEK1/2 and ERK1/2 were co-expressed in the LA of the mouse. So, we performed a western blot analysis on amygdala tissue extracts to check whether these activator (MEK1/2) and effector (ERK1/2) proteins were present. Our results showed that they are all present, allowing us to rule out a major difference between the mouse and the rat in the expression of these molecules, considered as the basis of amygdala-dependent neural processes leading to fear learning. Moreover, the relative abundance of all these four proteins with respect to the HPRT protein, used as loading control (data not shown), suggested that these ERK/MAPK signaling pathway members are not showing a major difference in their relative protein expression levels; this is in contrast with what we observed previously in an in situ hybridization study, where Mek2 was not detectable in most of the regions of the adult mouse brain (Di Benedetto et al, 2007). It could very well be the case that, in our previous study, the mRNA level for MEK2 was not high enough to be detected by ISH analysis, as it could be quickly translated and degraded; thus, making its level too low for detection through ISH, but allowing enough protein to be produced for detection through WB. It is indeed described that the turnover of mRNAs can vary depending on their $3^{\prime}$ UTRs (for a review, see Chen and Shyu, 1995 and Mitchell and Tollervey, 2000). Thus, in this line, depending on their mRNA structures, these four different molecules could show such a differential expression between transcriptional and translational levels. But only further specific biochemical studies could eventually clarify this point.

The Time Course of ERK/MAPK Activation in the LA of the Mouse Follows a Specific Pattern and is Dependent on Associative Tone-Shock Pairing

To study when processes responsible for acquisition or consolidation of fear memories occur, we decided to perform a time course of activation of pMAPK in the LA after fear conditioning. As controls to identify basal levels of activated PMAPK, we used animals that were exposed to the conditioning boxes, but not to tone/shock pairings. Thus, any activation of ERK/MAPK induced by nonassociative memory components, such as stress from handling or context exposure, would be included in cell counts of baseline controls. To evaluate whether eventual changes in activated pMAPK basal levels could be specifically ascribed to tone-shock pairings and not to unspecific effects due to only tone- or only shock-responsiveness, we next examined the cell count of pMAPK after 'tone alone', 'shock alone', or explicitely 'unpaired' tone-shock presentations. Our analysis could reveal that there was indeed a difference between the rat and the mouse in the peaks of PMAPK in LA. Consistent with the results shown in rats (Paul et al, 2007; Schafe et al, 2000), there was a peak in the number of phospho-labeled cells at $60 \mathrm{~min}$ after fear conditioning, which went down again to basal levels by $180 \mathrm{~min}$ (Figure 2b). These results were due to the specificity of tone-shock pairings, as the control experiment (Figure 3a) showed that only the peak of activation in the 'paired' group was significantly higher than the Box ctrl group. In contrast with Paul et al (2007), who found in the rat a second peak of activation at $5 \mathrm{~min}$ after fear conditioning, even higher than the one at $60 \mathrm{~min}$, we could not find any evidence for this second peak of phospho-activated labeled cells in the mouse (Figure 2b). As reviewed in Whishaw et al (2001), several comparative studies already described anatomical and behavioral differences between the mouse and the rat in their performance in various behavioral tests. Therefore, researchers have an increasing awareness that these differences may complicate and limit the use of rat studies to interpret findings in mice (Asan et al, 2005; Jardim et al, 1999). Consequently, experimental procedures have to be adapted to analyze behavioral responses in these two species. Indeed, there are several differences in the conditioning protocols used by Paul et al (2007) in comparison with our study. In particular, the number of tone/shock presentations, intensity, and duration of the 
footshocks as well as tone frequency and intensity differed. These differences may account for the different results obtained in the time course of activated PMAPK in the two studies. Nevertheless, the persistence of a peak of activated pMAPK at $60 \mathrm{~min}$ after fear conditioning in both species suggests that a more general mechanism, strongly conserved across species, could be responsible for this activation, even though different conditioning protocols are applied. It has to be verified if possibly the peak of activated pMAPK at $5 \mathrm{~min}$ after conditioning could be ascribed to any unspecific nonassociative factors that were excluded in this study and the one by Schafe et al (2000) only for the $60 \mathrm{~min}$ time point.

\section{Activation of ERK/MAPK in the LA of the Mouse is Necessary for the Acquisition of the FPS Response}

Analysis of acquisition of cue-potentiated startle. The MAPK signaling pathway is already considered as a pharmacological target in the clinic in some neuropsychiatric diseases as the Bipolar Disorder. Among the treatments of choice, the mood stabilizers valproic acid or lithium have shown their effects in inhibiting the MAPKs (for a review, see Coyle and Duman, 2003). The present finding of pharmacological inhibition of FPS acquisition by an MEK inhibitor shows that the ERK/MAPK signaling pathway is directly involved in the acquisition of conditioned fear using the FPS procedure in mice. This goes in line with a previous report where the analysis of the knockout mouse for CREB, a known target of the ERK/MAPK, shows impairment in the acquisition of FPS (Falls et al, 2000). Moreover, the results from the misplaced injected animals confirm not only the specificity of the pharmacological inhibition effect on the amygdala, but also that the manipulation itself does not exert a general effect on perception of the US.

Analysis of acquisition of context-potentiated startle. Although changes in baseline startle responses due to contextual memory formation can have an impact on percentage scores of response to CS using proportional increase scoring methods (Walker and Davis, 2002), the comparison between the results presented in Figure $4 \mathrm{~b}$ and $d$ show that this impact is not affecting the specific inhibition of acquisition of an FPS response in amygdala U0126-injected mice (Figure 4b). In fact, although both vehicle- and U0126-injected animals show a trend to increases in context-potentiated baseline startle responses (Figure 4d), only the U0126-injected animals display inhibition in acquisition of the cue-potentiated startle response (Figure $4 \mathrm{~b}$ ). This confirmed both the specificity of the injection site and the effect of pharmacological inhibition on cue-driven potentiation. Interestingly, even though there is a context potentiation, pMAPK-labeled cells did not show increases in the LA after shock-alone exposure in the time-course analysis, as might be expected after contextual fear learning. An explanation for this could be that the time course of contextual learning is different from cue learning as hypothesized by Schafe et al (2000), or that the LA is not directly involved in these processes. Future experiments will be necessary to determine precisely whether contextual fear conditioning exerts similar effects as cue conditioning on ERK/MAPK activation in the LA.

\section{The Peak of ERK/MAPK Activation in the LA is Specifically Neuronal}

In recent years, the involvement of glia cells in active processes regulating neuronal function at the synaptic level has become more and more evident. Namely, it was shown that glia cells participate actively in regulating $\mathrm{Ca}^{2+}$ mediated glutamate release/recycling during synaptic communication (Ge et al, 2006; Parpura and Haydon, 2000). Our results show that the PMAPK activated in the LA $60 \mathrm{~min}$ after fear conditioning are not in glia cells, but only in neurons. But our analysis was limited to this time point, when the activation is most prominent, as we showed. As far as glia cells are involved in regulating activity of neurons (for a review, see Seifert et al 2006), controlling, for example, their synaptic strength, it is possible that MAPKs still play a role in glia cells, but at different time points after conditioning; the latter serving as, for example, a protective mechanism to restore baseline conditions after a peak of activity, reducing the excess of inter-synaptic glutamate that could result in neurotoxic effects (Gegelashvili and Schousboe, 1997; Kanai, 1997; Nicholls and Attwell, 1990; Rothstein et al, 1996; Tanaka et al, 1997).

In conclusion, our findings, together with other reports in literature, propose the ERK/MAPK signaling pathway as a valid biological target in the attempt to intervene in anxiety disorders. In particular, they make an important contribution toward validating the mouse as a model for studying the aetiopathogenesis of neuropsychiatric diseases.

\section{ACKNOWLEDGEMENTS}

BDB is particularly indebted with Dr Vera Pedersen for her generous support with surgery and histological analysis in the first phases of the pharmacological studies; and with Johanna Neumann for helping with the IHC during the analysis of the time course of activated pMAPK. This work has been funded by the Federal Ministry of Education and Research (BMBF) in the framework of the National Genome Research Network (NGFN), Förderkennzeichen 01GR430, and by the European Union (FP6, EUMODIC, LSHG-CT2006-037188). We are responsible for the contents of this publication.

BDB performed the experiments, participated in the design of the study and wrote the manuscript. MK gave her contribution in the statistical analysis and with the FPS experiments. DMVW participated in the supervision of the histological procedures. WAF gave his contribution in the establishment of the FPS procedures. SMH and WW participated in the design and coordination of the study. All authors read and approved the final manuscript.

\section{DISCLOSURE/CONFLICT OF INTEREST}

The authors declare no competing financial interest. 


\section{REFERENCES}

Asan E, Yilmazer-Hanke DM, Eliava M, Hantsch M, Lesch KP, Schmitt A (2005). The corticotropin-releasing factor (CRF)system and monoaminergic afferents in the central amygdala: investigations in different mouse strains and comparison with the rat. Neuroscience 131: 953-967.

Baas JM, Grillon C, Bocker KB, Brack AA, Morgan III CA, Kenemans JL et al (2002). Benzodiazepines have no effect on fear-potentiated startle in humans. Psychopharmacology (Berl) 161: 233-247.

Baekelandt V, Claeys A, Cherepanov P, De Clercq E, De Strooper B, Nuttin B et al (2000). DNA-dependent protein kinase is not required for efficient lentivirus integration. J Virol 74: 11278-11285.

Bauer EP, Schafe GE, LeDoux JE (2002). NMDA receptors and L-type voltage-gated calcium channels contribute to long-term potentiation and different components of fear memory formation in the lateral amygdala. J Neurosci 22: 5239-5249.

Bitsios P, Philpott A, Langley RW, Bradshaw CM, Szabadi E (1999). Comparison of the effects of diazepam on the fear-potentiated startle reflex and the fear-inhibited light reflex in man. J Psychopharmacol 13: 226-234.

Blair HT, Schafe GE, Bauer EP, Rodrigues SM, LeDoux JE (2001). Synaptic plasticity in the lateral amygdala: a cellular hypothesis of fear conditioning. Learn Mem 8: 229-242.

Chen CY, Shyu AB (1995). AU-rich elements: characterization and importance in mRNA degradation. Trends Biochem Sci 20: 465-470.

Coyle JT, Duman RS (2003). Finding the intracellular signaling pathways affected by mood disorder treatments. Neuron 38: 157-160.

Cryan JF, Holmes A (2005). The ascent of mouse: advances in modelling human depression and anxiety. Nat Rev Drug Discov 4: 775-790.

Davis M (1992). The role of the amygdala in fear and anxiety. Annu Rev Neurosci 15: 353-375.

Di Benedetto B, Hitz C, Holter SM, Kuhn R, Vogt Weisenhorn DM, Wurst W (2007). Differential mRNA distribution of components of the ERK/MAPK signalling cascade in the adult mouse brain. J Comp Neurol 500: 542-556.

Falls WA (2002). Fear-potentiated startle in mice. Curr Protoc Neurosci 8.11B.1-8.11B.16.

Falls WA, Carlson S, Turner JG, Willott JF (1997). Fear-potentiated startle in two strains of inbred mice. Behav Neurosci 111: 855-861.

Falls WA, Kogan JH, Silva AJ, Willott JF, Carlson S, Turner JG (2000). Fear-potentiated startle, but not prepulse inhibition of startle is impaired in CREBalphadelta ${ }^{-I-}$ mutant mice. Behav Neurosci 114: 998-1004.

Ge W, Yang XJ, Zhang Z, Wang HK, Shen W, Deng QD et al (2006). Long-term potentiation of neuron-glia synapses mediated by Ca2+-permeable AMPA receptors. Science 312: 1533-1537.

Gegelashvili G, Schousboe A (1997). High affinity glutamate transporters: regulation of expression and activity. Mol Pharmacol 52: 6-15.

Grillon C, Ameli R, Goddard A, Woods SW, Davis M (1994). Baseline and fear-potentiated startle in panic disorder patients. Biol Psychiatry 35: 431-439.

Grillon C, Ameli R, Woods SW, Merikangas K, Davis M (1991). Fear-potentiated startle in humans: effects of anticipatory anxiety on the acoustic blink reflex. Psychophysiology 28: 588-595.

Gundersen HJ, Bagger P, Bendtsen TF, Evans SM, Korbo L, Marcussen $\mathrm{N}$ et al (1988). The new stereological tools: disector, fractionator, nucleator and point sampled intercepts and their use in pathological research and diagnosis. APMIS 96: 857-881.
Heldt S, Sundin V, Willott JF, Falls WA (2000). Posttraining lesions of the amygdala interfere with fear-potentiated startle to both visual and auditory conditioned stimuli in C57BL/6J mice. Behav Neurosci 114: 749-759.

Jardim MC, Nogueira RL, Graeff FG, Nunes-de-Souza RL (1999). Evaluation of the elevated T-maze as an animal model of anxiety in the mouse. Brain Res Bull 48: 407-411.

Kanai Y (1997). Family of neutral and acidic amino acid transporters: molecular biology, physiology and medical implications. Curr Opin Cell Biol 9: 565-572.

Kaufman J, Charney D (2000). Comorbidity of mood and anxiety disorders. Depress Anxiety 12(Suppl 1): 69-76.

LaBar KS, Gatenby JC, Gore JC, LeDoux JE, Phelps EA (1998). Human amygdala activation during conditioned fear acquisition and extinction: a mixed-trial fMRI study. Neuron 20: 937-945.

Mitchell P, Tollervey D (2000). mRNA stability in eukaryotes. Curr Opin Genet Dev 10: 193-198.

Nicholls D, Attwell D (1990). The release and uptake of excitatory amino acids. Trends Pharmacol Sci 11: 462-468.

Nishiyama H, Knopfel T, Endo S, Itohara S (2002). Glial protein S100B modulates long-term neuronal synaptic plasticity. Proc Natl Acad Sci USA 99: 4037-4042.

Parpura V, Haydon PG (2000). Physiological astrocytic calcium levels stimulate glutamate release to modulate adjacent neurons. Proc Natl Acad Sci USA 97: 8629-8634.

Paul S, Olausson P, Venkitaramani DV, Ruchkina I, Moran TD, Tronson N et al (2007). The striatal-enriched protein tyrosine phosphatase gates long-term potentiation and fear memory in the lateral amygdala. Biol Psychiatry 61: 1049-1061.

Paxinos G, Franklin KBJ (2001). The Mouse Brain in Stereotaxic Coordinates, 2nd edn. Academic Press: San Diego, CA, USA.

Phelps EA, O’Connor KJ, Gatenby JC, Gore JC, Grillon C, Davis M (2001). Activation of the left amygdala to a cognitive representation of fear. Nat Neurosci 4: 437-441.

Rattiner LM, Davis M, French CT, Ressler KJ (2004). Brain-derived neurotrophic factor and tyrosine kinase receptor B involvement in amygdala-dependent fear conditioning. $J$ Neurosci 24: 4796-4806.

Risbrough VB, Brodkin JD, Geyer MA (2003). GABA-A and 5-HT1A receptor agonists block expression of fear-potentiated startle in mice. Neuropsychopharmacology 28: 654-663.

Roberson ED, English JD, Adams JP, Selcher JC, Kondratick C, Sweatt JD (1999). The mitogen-activated protein kinase cascade couples PKA and PKC to cAMP response element binding protein phosphorylation in area CA1 of hippocampus. J Neurosci 19: 4337-4348.

Rothstein JD, Dykes-Hoberg M, Pardo CA, Bristol LA, Jin L, Kuncl RW et al (1996). Knockout of glutamate transporters reveals a major role for astroglial transport in excitotoxicity and clearance of glutamate. Neuron 16: 675-686.

Schafe GE, Atkins CM, Swank MW, Bauer EP, Sweatt JD, LeDoux JE (2000). Activation of ERK/MAP kinase in the amygdala is required for memory consolidation of pavlovian fear conditioning. J Neurosci 20: 8177-8187.

Schafe GE, Nadel NV, Sullivan GM, Harris A, LeDoux JE (1999). Memory consolidation for contextual and auditory fear conditioning is dependent on protein synthesis, PKA, and MAP kinase. Learn Mem 6: 97-110.

Schafe GE, Nader K, Blair HT, LeDoux JE (2001). Memory consolidation of Pavlovian fear conditioning: a cellular and molecular perspective. Trends Neurosci 24: 540-546.

Seifert G, Schilling K, Steinhauser C (2006). Astrocyte dysfunction in neurological disorders: a molecular perspective. Nat Rev Neurosci 7: 194-206.

Tanaka K, Watase K, Manabe T, Yamada K, Watanabe $\mathrm{M}$, Takahashi $\mathrm{K}$ et al (1997). Epilepsy and exacerbation of brain injury in mice lacking the glutamate transporter GLT-1. Science 276: $1699-1702$. 
Thomas KL, Hunt SP (1993). The regional distribution of extracellularly regulated kinase- 1 and -2 messenger RNA in the adult rat central nervous system. Neuroscience 56: 741-757.

Todd KJ, Serrano A, Lacaille JC, Robitaille R (2006). Glial cells in synaptic plasticity. J Physiol Paris 99: 75-83.

Valjent E, Pages C, Hervé D, Girault JA, Caboche J (2004). Addictive and non-addictive drugs induce distinct and specific patterns of ERK activation in mouse brain. Eur J Neurosci 19: 1826-1836.
Walker DL, Davis M (2002). Quantifying fear potentiated startle using absolute versus proportional increase scoring methods: implications for the neurocircuitry of fear and anxiety. Psychopharmacology (Berl) 164: 318-328.

Whishaw IQ, Metz GA, Kolb B, Pellis SM (2001). Accelerated nervous system development contributes to behavioral efficiency in the laboratory mouse: a behavioral review and theoretical proposal. Dev Psychobiol 39: 151-170.

Supplementary Information accompanies the paper on the Neuropsychopharmacology website (http://www.nature.com/npp) 